\title{
ACTIVIDADES 2012
}

2do. Congreso Internacional de la Red Iberoamericana de Apego (RIA)

"Nuevas Evidencias, Modelos e Intervenciones en el Desarrollo del Apego a través del Ciclo Vital" 9 al 14 de Enero de 2012

Santiago de Chile.

XIII Simposio sobre Trastornos Bipolares

27 de Enero de 2012

Barcelona, España

Congreso Internacional "Feminismo y migración. Intervención social y acción pública (FEMIGRA)" 9 al 11 de Febrero de 2012

Barcelona, España

Conferencia Temática de la Asociación Mundial de Psiquiatría "Salud Mental y Medicina de Familia, trabajando juntos"

8 al 11 de febrero de 2012

Granada, España

14th National Conference: Dementias 2012

09 al 10 de Febrero de 2012

Londres, Reino Unido

II Congreso Internacional de Psicología y Educación 2012

Modelos Preventivos. Una mirada interdisciplinaria a una comprensión de los derechos humanos

13 al 16 de Marzo de 2012

Ciudad de Panamá.

VIII Jornadas Científicas de Investigación sobre Personas con Discapacidad "Cambio organizacional y apoyo a las graves afectaciones: dos prioridades"

14 al 16 de Marzo de 2012

Salamanca, España

XIII Congreso Nacional y I Foro Mediterráneo de Psicología de la actividad física del deporte

21 al 24 de Marzo

Murcia, España

XIV Congreso Argentino De Psicología

“Los Malestares De La Época"

12 al 14 de Abril de 2012

Salta, Argentina.

6 Congreso Latinoamericano y del Caribe (COMLAT / IAGG)

Envejecimiento y Salud desde la Región.

Del 06 al 09 de Abril de 2011.

Buenos Aires, Argentina

8th International Congress on Mental Dysfunction In Parkinson Disease

3 al 6 de mayo de 2012

Berlin, Alemania

Jornada Argentina de Psicologia de la Salud

"Psicosalud"

14 de mayo de 2011.

Buenos Aires, Argentina

$5^{\circ}$ Congreso Mundial de Salud Mental y Sordera "Un encuentro hacia el bienestar"

23 al 25 de Mayo 2012

Monterrey, México 
IX Congreso Argentino de Psicoanálisis

24 al 26 de Mayo

Mendoza, Argentina

Congreso de la Sociedad Interamericana de Psicología

21 al 23 de Junio de 2012.

Santa Cruz de la Sierra, Bolivia.

IV Conferencia Internacional de Psicología Comunitaria

21 al 23 de Junio de 2012

Barcelona, España

XVIII Congreso Internacional de Psicoterapia Grupal y Procesos Grupales (IAGP)

16 al 21 de Julio

Cartagena, Colombia

Educación y Pedagogía Especial

9 al 13 de Julio de 2012

Cuba

$30^{\circ}$ Congreso Internacional de Psicología "Psicología sirviendo a la humanidad"

22 al 27 de Julio 2012

Ciudad del Cabo, Sudáfrica

120th Annual Convention of the American Psychological Association

2 al 5 de Agosto de 2012.

Chicago, EUA

XI Congreso Europeo de Sexología.

20 al 22 de Septiembre de 2012.

Madrid, España

XVI Congreso Latinoamericano de Sexología y Educación Sexual "Sexualidad: ciencia y arte del nuevo milenio" 10 al 13 de Octubre de 2012

Medellín, Colombia 